\title{
Prevalence and Intensity of Urinary Schistosomiasis Among Selected People in Tulus Area, South Darfur State, Sudan
}

\section{A Maki}

Department of Molecular Genetics, Institute of molecular Biology, University of Nyala

\section{Gafar A Ali}

State Ministry of Health, Center of Disease Control, Nyala, South Darfur

Khalid Hajissa ( $\sim$ khalid541983@yahoo.com )

Omdurman Islamic University https://orcid.org/0000-0002-1725-6702

\section{Research note}

Keywords: Schistosoma haematobium, South Darfur State, Gross haematuria, egg intensity, Sudan

Posted Date: June 2nd, 2020

DOI: https://doi.org/10.21203/rs.3.rs-31736/v1

License: (c) (i) This work is licensed under a Creative Commons Attribution 4.0 International License.

Read Full License 


\section{Abstract}

Objective: Urinary schistosomiasis is a major public health issue in Sudan. The disease is endemic in many rural communities across the country. This is a cross-sectional study conducted to determine the prevalence and intensity of urinary schistosomiasis among selected induvial in the city of Tulus, South Darfur state, Sudan. One hundred terminal urine samples were collected and examined for Schistosoma haematobium eggs using standard filtration technique.

Results: A total of 100 individual were enrolled in the study with a mean $( \pm$ SD) age of $17.7 \pm 0.73$ years. Out of them, $62(62 \%)$ were found to be infected with Schistosoma haematobium. The statistical analysis showed significant association with gender $(P=0.043)$ with higher prevalence $70.9 \%(39 / 55)$ in female than males $51.1 \%(23 / 45)$. Majority of the $S$. haematobium infections were classified as intense infection $(82 \%, 51 / 62)$ with egg count $\geq 50$ eggs/ $10 \mathrm{ml}$ urine, while gross haematuria was observed in $10 \%$ of urine samples. Further studies, including large sample size will be essential to assess the burden of the disease in the study area.

\section{Introduction}

Urinary schistosomiasis is a chronic water-dependent parasitic disease caused by the trematode Schistosoma haematobium (S. haematobium) (1). It is the one of most devastating prevalent neglected tropical parasitic diseases (NTDs) due to the high morbidity and mortality rate among susceptible population in developing countries particularly in Africa (2). The poor sanitation and inadequate hygiene (WASH) as well as the lack of access to clean water are major contributors to the burden of the disease (3).

In endemic tropical and subtropical countries, the disease remains as a major public health problem. The high prevalence of schistosomiasis placed it as second most important parasitic disease with public health problem after malaria (4). In the 74 endemic countries, an estimated of 250 million people are infected while approximately 700 million people are at risk of getting the infection (4). In Africa and Middle East $S$. haematobium is widespread with more than 110 million infected people [6]. In addition, $S$. haematobium is the cause of nearly two-thirds of schistosomiasis cases resulted in long-term and severe complications (5).

Deposition of the $S$. haematobium eggs in tissues can cause progressive damage particularly in the bladder, ureters and kidney. The potential consequences of the infection includes haematuria (blood in urine), dysuria (painful urination), nutritional deficiencies and lesions of the urinary bladder (4). Furthermore, increasing evidence supports that the infection can lead to infertility, cancer, kidney failure and increased susceptibility to HIV. While children might experience anaemia and physical weakness which consequently reduce their learning ability (6)

Despite the intensive efforts to control the disease, it is still persists. Many reports stated that urinary schistosomiasis is endemic in Sudan. It was first reported in the country in 1904. Since then, various 
epidemiological studies indicated the presence of the disease in all regions of the country $(7,8)$.

A recent nationwide survey carried out in all the states estimated that the overall prevalence of $S$. haematobium was $5.2 \%$. The same survey pointed East and South Darfur States as most severe endemic areas (9). However, there are limited data on the burden of the disease in these areas. This could be attributed to the civil war in the region as the prevention and control during conflict are often neglected.

Although, in the 1970s, schistosomiasis was reported to be endemic in the western area of Darfur [9], there have been few detailed surveys and published data in this region, particularly during the years overwhelmed by the civil war. Therefore, this study was conducted to provide preliminary information in regard to $S$. haematobium prevalence in a limited study population recruited form the city of Tulus, South Darfur state which can help in improving schistosomiasis control in the area.

\section{Methodology}

\section{Study design and Study site}

This is cross-sectional study carried out during May 2018 to estimate the prevalence of S. haematobium in Tulus area. South Darfur State, Sudan.

\section{Study participants and Sample collection}

A total of 100 participants with different ages from both sex ( $45 \%$ males and $55 \%$ females) were enrolled in this Study. After informed consent was obtained, about $10 \mathrm{ml}$ of urine samples were collected from each subject.

\section{Laboratory investigation}

The urine samples were first observed whether show occult or gross hematuria, and then examined for the presence of $S$. haematobium eggs by membrane filtration technique as described previously [10]. In brief: all urine samples of sufficient quantity were shaken, subsequently, $10 \mathrm{ml}$ of each sample were pressed through a polycarbonate filter with a pore size of $20 \mu \mathrm{m}$ (Sterlitech, Kent, WA, USA) using a standard $10 \mathrm{ml}$ plastic syringe, the membrane was then put on a microscope slide, covered with a piece of hydrophilic cellophane soaked in glycerol solution, and examined under the microscope by trained laboratory technicians using some drops of Lugol's iodine to stain S. haematobium eggs after cellophane coverage. The presence and number of $S$. haematobium eggs was recorded. After microscopy, the slides were stored for second reading for quality control.

The number of $S$. haematobium eggs per filter was quantified; the intensity of the infection was classified as light (1-49 eggs/10 $\mathrm{ml}$ of urine) or heavy ( $\geq 50$ eggs/10 $\mathrm{ml}$ of Urine), as defined by the World Health Organization [19].

\section{Statistical analysis}


The collected data were stored, double checked and analyzed using Statistical package for social science (SPSS) version 22.0 (Inc. Chicago, I.USA). Chi Square test was used for ordinal variables to find the significant differences between several categories and determination of the prevalence (as \%), with Pvalues of, 0.05 being considered indicative of a statistically significant difference.

\section{Results}

A total of 100 individuals ( 45 males and 55 females) were enrolled from the city of Tulus. The respondents were from the age group of 3-42 years with a mean (SD) age of $17.7(0.73)$ years. The overall prevalence of $S$. haematobium among respondents was $62 \%(62 / 100)$. The prevalence was $51.1 \%$ $(23 / 45)$ and $70.9 \%(39 / 55)$ for the male and female respectively. However the prevalence of the disease was high in the females than males and there was a significance difference in the prevalence rate $(P$ $=.043$ ), and they were not significantly more likely to have intense infections with this parasite.

Majority of the $S$. haematobium infections were classified as intense infection $(82 \%, 51 / 62)$ with egg count $\geq 50$ eggs $/ 10 \mathrm{ml}$ urine. In addition, gross haematuria was observed in $10 \%$ of urine samples. A positive correlation between the haematuria and intensity of eggs was revealed $(P$. value $=.000)($ Table 1$)$.

\begin{tabular}{|llll}
\hline \multirow{3}{*}{ Haematuria } & \multicolumn{1}{c}{ Haematuria } & Egg count \\
\cline { 2 - 4 } & \multicolumn{1}{l}{ Pearson Correlation } & 1 & $-.655^{\star *}$ \\
\cline { 2 - 4 } & Sig. (2-tailed) & .000 \\
\cline { 2 - 4 } & $\mathrm{N}$ & 100 & 100 \\
\hline \multirow{2}{*}{ Egg count } & Pearson Correlation & $-.655^{\star *}$ & 1 \\
\cline { 2 - 4 } & Sig. (2-tailed) & .000 & \\
\cline { 2 - 4 } & $\mathrm{N}$ & 100 & 100 \\
\hline \multirow{2}{*}{ **. Correlation is significant at the 0.01 level (2-tailed). } \\
\hline
\end{tabular}

Table 1

Correlation between the haematuria and egg count

\section{Discussion}

In Sudan, schistosomiasis remains a life-threatening public health problem with an estimation of more than eight million people at risk of infection. Thus, Sudanese government prioritised collecting data on the burden of NTDs, particularly schistosomiasis. In response; many epidemiological studies were conducted in central and east Sudan $(10,11)$, with relatively few, if any, such studies being conducted in Darfur area. 
Therefore, this study was conducted to estimate the prevalence and intensity of $S$. haematobium infection in selected populations from the city of Tulus, South Darofur State. The study revealed that the percentage of infected people with $S$. haematobium infection based on urine filtration method was $62 \%$ $(62 / 100)$. The high observed prevalence of urinary schistosomiasis $(62 \%)$ was relatively in agreement with the study conducted by Deribe et al. (2011) in the same state whose reported a rate of $56 \%$ of infection among the respondents (12). Similarly, remarkably high prevalence (80.6\%) was also reported in Gereida Camp, South Darfur (13).

The high prevalence could be attributed to the high exposure and dependence of the people in the area on open water sources for drinking and household purposes $(12,14)$. The adaptation of intermediate host (Bulinus truncates) to pools and slow-flowing waters in South Darfur area reflect consideration of these water bodies to be potential transmission sites for the disease (15). In addition, the fact that these small ponds in entire area are used for fishing, bathing, and swimming increase the risk of getting the infection.

In contrast, the present study showed very much higher prevalence of $S$. haematobium compared to that obtained from nationwide survey (5.2\%), even though, South Darfur States was the second most endemic area with a prevalence of $13.91 \%$ in that survey (9). Moreover, many other finding across the country reported lower findings when the $S$. haematobium diagnostic stages were screened particularly among children $(11,16,17)$. Such as that of Hajissa et al. $(2018)$ in Um-Asher Area, Khartoum State; Sulieman et al. (2017) in Alsaial Alsagair Village, River Nile State, and Abou-Zeid et al. (2013) in Southern Kordofan State $(8,18,19)$.

Worldwide, similar observation of high Egg positive rate was also made in Senegal (57.6\%) (1), while in many other country the rates were slightly lower such as those reported from Nigeria (48\%), Gabon (45\%), Malawi $(10.4 \%)(4,6,20)$. This variation could be due to study period, target population, environmental condition, sample size variations and the method of laboratory diagnosis.

With regard to the intensity of the infection, majority of the $S$. haematobium infections $(82 \%, 51 / 62)$ were of intense infection ( $\geq 50$ eggs/10 $\mathrm{ml}$ urine). This finding agrees with previous reports $(1,4)$ where the intensity was classified as high. However, light infection intensity was also reported (21). The variation between areas could be explained by the frequency of people contact with contaminated water bodies, burden of the adult worms hosted as well as the differences in environmental setting and culture. As a consequence of the high prevalence with heavy $S$. haematobium infection haematuria was observed in the current study, and there was a positive correlation between the haematuria and intensity of eggs $(P$. value $=.000$ ), this result is in line with result of Ismail et al.,2014 (22) [16]. Indeed the observed hematuria could be attributed to the heavy egg intensity reported among the study participants

In conclusion: the very high prevalence of $S$. haematobium infection observed in the study area, indicate that the city of Tulus is endemic for urinary schistosomiasis, with a high intensity of infection. Therefore, integrated control program and prevention measures need to be implemented in the study area. 


\section{Limitations}

Despite the slightly high prevalence of $S$. haematobium infection among the study participants. The study was limited by the small sample size. The estimated prevalence cannot reflect the burden of the disease among the whole population at the village/town level unless wide survey with large sample size is done.

\section{Abbreviations}

S. haematobium: Schistosoma haematobium, NTDs: Neglected Tropical Parasitic Diseases, SD: standard deviation, ml: milliliter.

\section{Declarations}

\section{Ethics approval and consent to participate}

The study protocol was reviewed and approved by the Research committee of the Institute of Molecular Biology, university of Nyala, and the South Darfur Ministry of Health, Sudan. Prior the enrolment in the study, the aims and the methodology were discussed with every participant, accordingly, a written consent was obtained before sample collection.

\section{Consent for publication}

Not applicable.

\section{Availability of data and material}

All original or analyzed data for this study is available on request from the corresponding author.

\section{Competing interests}

The authors declare that they have no competing interests.

\section{Funding}

The study was not received any financial support

\section{Authors' contributions}


MA and AHS: conceived and designed the study and writing the Manuscript, GAA and KH: analyzed the data. All authors read and approved the final manuscript.

\section{Acknowledgements}

Authors would like to thanks University of Nyala, State Ministry of Health; Center of Disease control, Nyala, South Darfur, Sudan and Tulus Health Center staff for their helps and technical supports.

\section{References}

1. Senghor B, Diallo A, Sylla SN, Doucouré S, Ndiath MO, Gaayeb L, et al. Prevalence and intensity of urinary schistosomiasis among school children in the district of Niakhar, region of Fatick, Senegal. Parasit Vectors. 2014;3;7:5.

2. Okwori AJ, Sidi M, Ngwai Y, Obiekezie S, Makut M, Chollom S, et al. Prevalence of schistosomiasis among primary school children in Gadabuke District, Toto LGA, North Central Nigeria. Microbiology Research Journal International. 2014;255-61.

3. Erismann S, Diagbouga S, Odermatt P, Knoblauch AM, Gerold J, Shrestha A, et al. Prevalence of intestinal parasitic infections and associated risk factors among schoolchildren in the Plateau Central and Centre-Ouest regions of Burkina Faso. Parasit Vectors. 2016;9(1):554.

4. Dejon-Agobé JC, Edoa JR, Honkpehedji YJ, Zinsou JF, Adégbitè BR, Ngwese MM, et al. Schistosoma haematobium infection morbidity, praziquantel effectiveness and reinfection rate among children and young adults in Gabon. Parasit Vectors. 2019;12(1):1-11.

5. Li EY, Gurarie D, Lo NC, Zhu X, King CH. Improving public health control of schistosomiasis with a modified WHO strategy: a model-based comparison study. The Lancet Glob Health.. 2019;7(10):e1414-e22.

6. Muhammad IA, Abdullahi K, Bala AY. Prevalence of urinary schistosomiasis among primary school pupils in Wamakko Local Government, Sokoto State, Nigeria. The Journal of Basic and Applied Zoology. 2019;80(1):22.

7. Afifi A, Ahmed A-AA, Sulieman Y, Pengsakul T. Epidemiology of schistosomiasis among villagers of the New Halfa Agricultural Scheme, Sudan. Iran J Parasitol. 2016;11(1):110.

8. Hajissa K, Muhajir AEM, Eshag HA, Alfadel A, Nahied E, Dahab R, et al. Prevalence of schistosomiasis and associated risk factors among school children in Um-Asher Area, Khartoum, Sudan. BMC Res Notes. 2018;11(1):779.

9. Cha S, Elhag MS, Lee Y-H, Cho D-S, Ismail HAHA, Hong S-T. Epidemiological findings and policy implications from the nationwide schistosomiasis and intestinal helminthiasis survey in Sudan. Parasit Vectors. 2019;12(1):429.

10. Lee Y-H, Lee J-S, Jeoung H-G, Kwon I-S, Mohamed AAWS, Hong S-T. Epidemiological Survey on Schistosomiasis and Intestinal Helminthiasis among Village Residents of the Rural River Basin Area 
in White Nile State, Sudan. Korean J Parasitol. 2019;57(2):135.

11. Elsammani NA, Adam AA, Mater AA, Osman M. Prevalence Of Schistosomiasis Among School Children In Bahri Locality, Sudan. International Journal of Research - GRANTHAALAYAH. $2019 ; 7$ (9).

12. Deribe K, Eldaw A, Hadziabduli S, Kailie E, Omer MD, Mohammed AE, et al. High prevalence of urinary schistosomiasis in two communities in South Darfur: implication for interventions. Parasit Vectors. 2011;4(1):14.

13. Ahmed A, Afifi A, Adam I. High prevalence of Schistosoma haematobium infection in Gereida Camp, in southern Darfur, Sudan. Ann Trop Med Parasitol. 2009;103(8):741-3.

14. Sturrock HJ, Picon D, Sabasio A, Oguttu D, Robinson E, Lado M, et al. Integrated mapping of neglected tropical diseases: epidemiological findings and control implications for northern Bahr-elGhazal State, Southern Sudan. PLoS Negl Trop Dis. 2009;3(10).

15. Malek EA. Distribution of the intermediate hosts of bilharziasis in relation to hydrography: With special reference to the Nile Basin and the Sudan. Bulletin of the World Health Organization. 1958;18(5-6):691.

16. Taha Q, Elshazali O, Ahmed A. Distribution of urinary schistosomiasis among school children at elkeriab and tayba elkababish villages, East Nile Locality, Khartoum State, Sudan. J Pediatr Neonatal Care. 2019;9(4):117-9.

17. Muhajir A, Hajissa K, Mohamed Z, Aal A. Prevalence of Intestinal Parasitic Infection among Children in Al-kalakla, Khartoum, Sudan. World App/ Sci J. 2017;35(2):219-22.

18. Abou-Zeid AH, Abkar TA, Mohamed RO. Schistosomiasis infection among primary school students in a war zone, Southern Kordofan State, Sudan: a cross-sectional study. BMC Public Health. 2013;13(1):643.

19. Sulieman Y, Eltayeb RE, Pengsakul T, Afifi A, Zakaria MA. Epidemiology of urinary schistosomiasis among school children in the Alsaial Alsagair village, River Nile State, Sudan. Iran J Parasitol. 2017;12(2):284.

20. Kapito-Tembo AP, Mwapasa V, Meshnick SR, Samanyika Y, Banda D, Bowie C, et al. Prevalence distribution and risk factors for Schistosoma hematobium infection among school children in Blantyre, Malawi. PLoS Negl Trop Dis. 2009;3(1).

21. Degarege A, Mekonnen Z, Levecke B, Legesse M, Negash Y, Vercruysse J, et al. Prevalence of schistosoma haematobium infection among school-age children in afar area, Northeastern Ethiopia. PloS one. 2015;10(8).

22. Ismail HAHA, Hong S-T, Babiker ATEB, Hassan RMAE, Sulaiman MAZ, Jeong H-G, et al. Prevalence, risk factors, and clinical manifestations of schistosomiasis among school children in the White Nile River basin, Sudan. Parasit Vectors.. 2014;7(1):478. 